\title{
PARANEOPLASTIC ECZEMA AS AN INITIAL MANIFESTATION OF A RENAL CELL CARCINOMA
}

\author{
Vanya B. Georgieva ${ }^{1}$, Tsvetelina V. Markova ${ }^{2}$
}

\begin{abstract}
Paraneoplastic skin manifestations are well-known accompanying disorders in cases with a malignant tumor. If not treated, some may lead to serious disability. In fact, these conditions disappear after the tumor removal. Plantar hyperkeratosis as the first manifestation of clearcell renal cell carcinoma has not been reported. We present a patient with severe untreatable hyperkeratosis of the soles of the feet. The paraneoplastic etiology of the eczema was suggested, and a left kidney tumor was diagnosed and operated. Rapid improvement of the keratoderma eczema was observed within a week of the tumor removal. The patient has no local and distant metastases.

Paraneoplastic skin manifestations as initial syndromes of malignant disease can help in the early diagnosis of cancer at a stage that allows complete cure.
\end{abstract}

UDC Classification: 616, DOI: https://doi.org/10.12955/pmp.v2.167

Keywords: Renal cell carcinoma, Paraneoplastic syndrome, Kidney cancer

\section{Introduction}

Dermatological paraneoplastic syndromes and endocrine syndromes are the most common types of paraneoplastic syndromes (Silva, 2013). Paraneoplastic diseases with hormonal, neurological, hematological, or dermatological manifestations and clinical or biochemical disturbances are associated with the presence of malignancies without primary tumor invasion or metastasis (Stollmeier, 2016). The skin problems may alert the doctor for suggestive underlying systemic diseases, thus contributing to the diagnosis of many diseases, including malignancies (Silva, 2013, Ramos-E-Silva,2011, Pipkin, 2008). The recognition of some typical paraneoplastic dermatoses may lead to the early diagnosis of a neoplasm and determine a better prognosis (Silva, 2013).

\section{Objective}

Paraneoplastic syndromes can help for early diagnosis of a neoplasm. Paraneoplastic dermatoses are a heterogeneous group of clinical manifestations that may have a benign appearance. In the current paper, the authors report case of a 56-year-old woman presented with plantar paraneoplastic eczema, which identified the underlying clearcell renal cell carcinoma. After the diagnosis of the kidney tumor /CT and $\mathrm{MRI} /$ the patient underwent a radical tumor excision, and the syndrome of paraneoplastic eczema disappeared a week after the surgery.

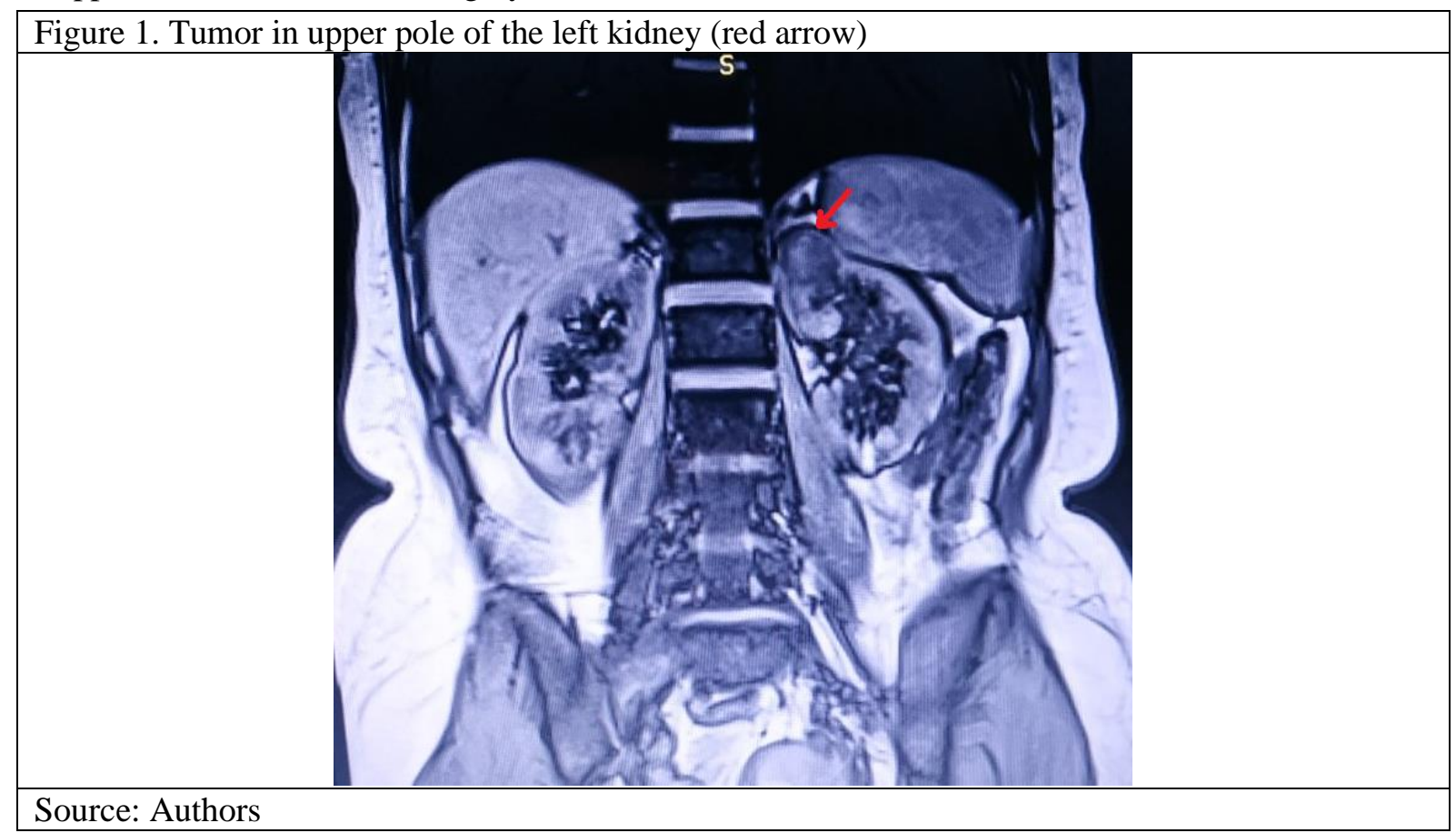

${ }^{1}$ Sofiamed Hospital, Sofia University St. Kliment Ohridski, Sofia, Bulgaria, docvania@abv.bg

${ }^{2}$ Sofiamed Hospital, Sofia University St. Kliment Ohridski, Sofia, Bulgaria, inita_markova@mail.bg 


\section{Case report}

A 56-year-old non-smoking woman with no history of the recent internal disease was presented with keratoderma eczema of the soles of the feet and dermatitis accompanied by an itchy rash on the skin of the feet. Local skin treatments were ineffective.

The patient was hospitalized with xerotic skin and deep linear cracks on both feet. Fungus tests were negative. Over 8 months, she was treated with local softening agents, lactic acid cream, anti-pruritus agents, and local steroid creams and unguents. All applied agents were without any benefit.

The paraneoplastic etiology of the eczema was suggested. A CT and MRI body examinations were performed, and a left kidney tumor was diagnosed (Fig.1). The patient was staged with pT1N0M0, and she underwent excision of the tumor. The pathology report was clearcell renal cell carcinoma.

Rapid improvement of the keratoderma eczema was observed within a week of removing the tumor (Fig.2).

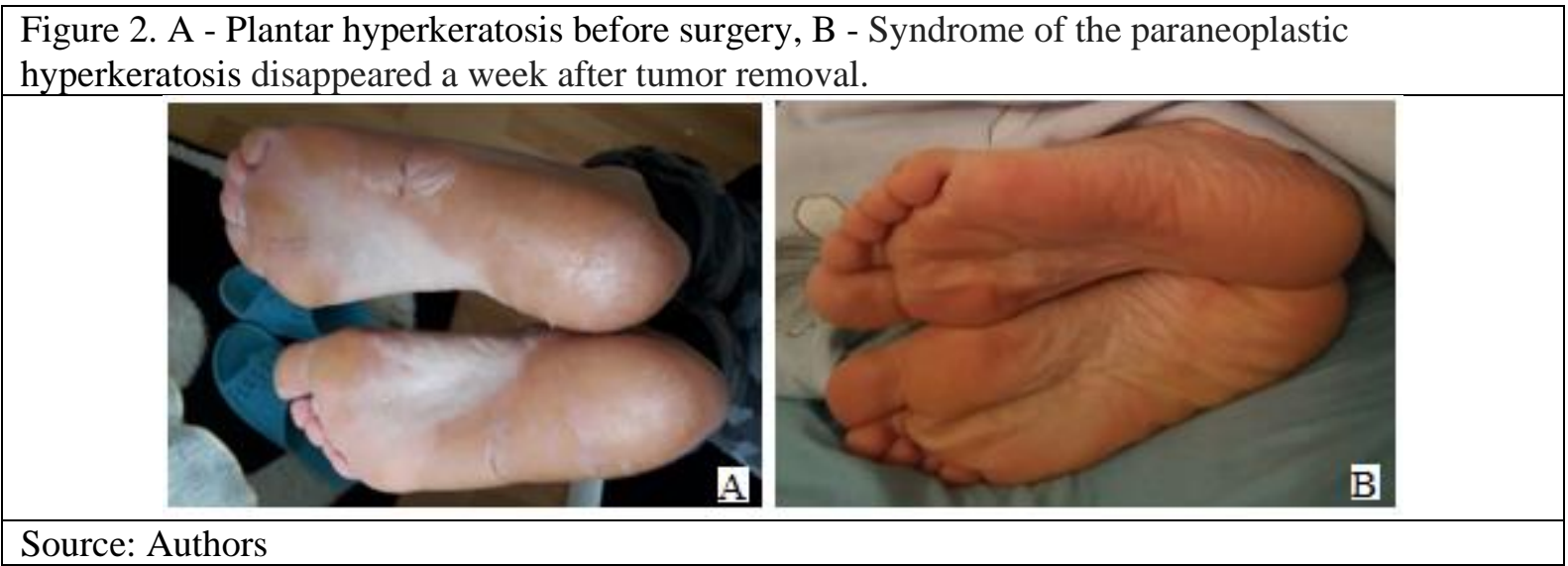

\section{Discussion}

Palmoplantar Keratoderma is a hyperkeratosis of the palms and soles of the feet. Keratoderma of hands and feet may represent a feature in a multitude of conditions. The condition could be congenital (genetic) and acquired (Shiller ,2014). The family history of palmoplantar keratoderma (PPK) may help establish the inheritance pattern. Differential diagnoses of hereditary PPK include Inflammatory disorders such as chronic dermatitis, lichen planus, psoriasis, or Reiter's syndrome. Some infectious causes include common warts, tinea, scabies, or syphilis (Has C, 2016). The marked thickening of the skin of the palms and soles can be a paraneoplastic syndrome related to an internal malignancy (HLers, 2009). Palmoplantar keratoderma can also be associated with malignancies as esophageal, gastric, pulmonary, and urinary/bladder carcinomas (Kallini, 2017).

In 1976, Curth proposed six criteria to identify Paraneoplastic dermatoses (Curth, 1976):

1. The onset of dermatosis and neoplasia start at the same time

2. Both conditions follow a parallel course

3. The dermatosis is not recognized as part of a genetic syndrome

4. A specific dermatosis occurs with a specific tumor

5. Cutaneous dermatosis is rare in the general population

6. A high grade of association with neoplasia is noted.

According to the presented criteria, the current case in the review is paraneoplastic dermatosis.

The cutaneous manifestations of internal cancer can develop either before or after the presence of the establishment of the underlying tumor. That is why inspection of the skin remains an essential part of the complete physical examination. Some dermatoses are highly correlated with malignancy, whose recognition implies a mandatory investigation of internal cancer. Since cutaneous paraneoplastic syndromes commonly precede or follow visceral cancer, their recognition may result in earlier diagnosis and better prognosis for the patient (Azulay, 2000, Dourmishev, 2009).

Paraneoplastic dermatoses which are associated 90-100\% with neoplasm, are called obligate paraneoplastic dermatosis, while in facultative paraneoplastic dermatoses, cancer can be detected in $25 \%-30 \%$ of the cases (Miyashiro, 2016, Khoschbin, 2019). Obligate paraneoplastic dermatoses are 
Acanthosis nigricans maligna, Necrolytic migratory erythema, Leser-Trelat's syndrome, Trousseau's syndrome, Paraneoplastic pemphigus, Acquired hypertrichosis lanuginose, Acrokeratosis paraneoplastica of Bazex, Erythema gyratum repens. Facultative paraneoplastic dermatoses are: Paraneoplastic dermatomyositis, Acquired palmoplantar keratoderma, Sweet syndrome, Pyoderma gangrenous, Pytiriasis rotunda, Multicentric reticulohistiocytosis, Anti-laminin 332 bullous pemphigoid (Miyashiro, 2016, Khoschbin, 2019). In the presented case, the plantar keratoderma is a facultative paraneoplastic dermatosis.

Patients with renal cell carcinoma present in up to $20 \%$ with paraneoplastic syndromes (Gold, 1996). The paraneoplastic syndromes associated with renal cell carcinoma range: Hypercalcemia, Amyloidosis, Hypertension, Anemia, Polycythemia, Neuromyopathies, Nonmetastatic hepatic dysfunction, Vasculopathy, Galactorrhea, Nephropathy, Cushing's syndrome, Coagulopathy, Alterations in glucose metabolism, Prostaglandin elevation (Palapattu, 2002). The skin syndromes in cases of renal tumor are rarely observed. There a few publications associating clearcell renal cell carcinoma and paraneoplastic skin disorders (Yan, 2013). This kind of association was observed in the presented case and the feet were affected separately without palms involvement.

Eczema and skin syndromes in neoplastic malignancies need to be diagnosed as such promptly. This gives patients a chance for early diagnosis of the tumor and a better result in terms of cancer prognosis, such as in the presented case.

\section{Conclusion}

Dermatological paraneoplastic syndromes are rare in cases of renal cell carcinoma (Yan, 2013). Yet they can be an early sign to identify the underlying tumor. These syndromes are definitively treated with tumor removal.

\section{References}

Azulay RD, Azulay DR, Abulafia LA. Sinais malignos na pele versus síndromes paraneoplásicas cutâneas: revisão. An Bras Dermatol. 2000;75:621-30.

Curth HO. Skin lesions and internal carcinoma. In: Andrade R, editor. Cancer of the Skin: Biology, Diagnosis, Management. 1976: $1308-41$

Dourmishev LA, Draganov PV. Paraneoplastic dermatological manifestation of gastrointestinal malignancies. World J Gastroenterol. 2009;15:4372-9.

Gold PJ, Fefer A, Thompson JA. (1996) Paraneoplastic manifestations of renal cell carcinoma. Semin Urol Oncol. Nov;14(4):216-22. PMID: 8946620.

Has Cristina, Technau-Hafsi Kristin (2016) Palmoplantar keratodermas: clinical and genetic aspects,

Journal der Deutschen Dermatologischen Gesellschaft, https://doi.org/10.1111/ddg.12930

HLers BH, Sahn RE, Callen JP (2009) Cutaneous manifestations of internal malignancy. CA: ACancer J Clinicians 59:73-98.

Kallini JR, Sadeghani K, Khachemoune A (2017) Paraneoplastic palmoplantar keratoderma secondary to metastatic uterine adenocarcinoma. Cutis 99: E32-5

Khoschbin T, Loser C, Dippel E. (2019) Paraneoplastic skin diseases. Internist, 60, 775-782.

Miyashiro D, Sanches JA. (2016)Paraneoplastic skin disorders: A review. G. Ital. Dermatol. Venereol., 151, 55-76.

Palapattu GS, Kristo B, Rajfer J. (2002) Paraneoplastic syndromes in urologic malignancy: the many faces of renal cell carcinoma. Rev Urol.;4(4):163-170.

Pipkin CA, Lio PA. (2008) Cutaneous manifestations of internal malignancies: an overview. Dermatol Clin.;26:1-15.

Ramos-E-Silva M, Carvalho JC, Carneiro SC. (2011) Cutaneous paraneoplasia. Clin Dermatol.;29:541-7.

Silva JA, Mesquita Kde C, Igreja AC, et al. (2013) Paraneoplastic cutaneous manifestations: concepts and updates. An Bras Dermatol.;88(1):9-22. doi:10.1590/s0365-05962013000100001

Schiller S, Seebode C, Hennies HC et al. Palmoplantar keratoderma (PPK): acquired and genetic causes of a not so rare disease. J Dtsch Dermatol Ges 2014; 12(9): 781-8.

Stollmeier A, Rosario BA, Mayer BL, et al. (2016) Seborrheic Keratoses as the First Sign of Bladder Carcinoma: Case Report of Leser-Trélat Sign in a Rare Association with Urinary Tract Cancer. Case Reports in Medicine:4259190. DOI: $10.1155 / 2016 / 4259190$.

Yan K, Liu C, Xu Z, Liu Z, Wang K, Jiang Y, Fan Y. (2013) Renal cell carcinoma presenting as exfoliative dermatitis (erythroderma) - a case report. Clin Nephrol.;80(1):63-6. doi: 10.5414/CN107319. PMID: 22575379. 